\title{
EVALUATING HOTEL ADVERTISEMENTS EFFICIENCY USING DATA ENVELOPMENT ANALYSIS
}

\author{
Yossi Hadad ${ }^{1}$ Lea Friedman² and Aviad A. Israeli ${ }^{3}$ \\ ${ }^{1}$ Department of Industrial Engineering and Management, Sami Shamoon College of Engineering, \\ Bialik/Basel Sts. P.O. Box 45 Beer Sheva 84100 Israel; \\ Phone:+972-8-647-564; Fax:+972-8-647-5643.E-mail:yossi@sce.ac.il \\ ${ }^{2}$ Department of Industrial Engineering and Management, Ben-Gurion University of the Negev, \\ Beer-Sheva,84105, Israel, E-mail: leaf@bgumail.ngu.ac.il \\ ${ }^{3}$ Department of Hotel and Tourism Management, Ben-Gurion University of the Negev, Beer-Sheva, 84105, Israel, \\ Phone:+972 8 6461254, Fax:+97286472920,E-mail: aviad@som.bgu.ac.il
}

Received:07 29 2005; accepted 09062005

\begin{abstract}
This paper introduces popular methods for ranking alternatives with multiple inputs and multiple outputs in the DEA context. The ranking methods are based on different criteria. Consequently, the ranking of the alternatives are not always the same, particularly as regards the best alternative. The decision maker, however, must make an absolute decision as to the most favored alternative. This study proposes a new ranking method, which is based on the average of the highly correlated ranking method. The new method is applied on a case study of ranking hotels in Israel.
\end{abstract}

Keywords: DEA, ranking models, advertising, hospitality.

\section{Introduction}

Countries throughout the world derive large parts of their respective gross national products (GNP) from the tourism and hospitality industries. Unfortunately, the increased threat of terrorism and general slowdown of the global economy has led to a decline in the consumption of tourism and hospitality goods and services. In their study of crisis management tactics and strategies, Israeli and Reichel (2004, in press) suggested that reliance on intensive advertising may be an effective component of crisis management strategy and may lead to increased consumption.

While advertising is an important component of any marketing strategy, it is important to ensure that advertising is done effectively. Effective communication in advertising requires that specified messages (attributes) be conveyed to potential customers and that the result will be a corresponding demand from these customers at a profitable price. With respect to attributes perceived as important by consumers, a study conducted by Mehrez and Israeli (2001) on the Israeli hospitality industry found that hotel guests expect a variety of services, including swimming pool and spa, activities for children, adult activities, sports facilities, and more. As part of the effort to attract different market segments, hotels often communicate the abovementioned attributes in advertisements. To consider an advertisement effective, a firm should be able to use what is being advertised (such as characteristics of the product or service) as justification for the price it requests and also to be able to secure a purchase from customers (Barta Myers and Aaker, 1996).

To examine the effectiveness of advertising to the hotel industry, this paper uses a real case in the Israeli hospitality industry and evaluates the effectiveness of an advertising supplement dedicated to promoting hotels that appeared in a national newspaper. Effectiveness was evaluated using different ranking models of Data Envelopment Analysis (DEA) procedures. In this context, the effectiveness of hotel advertisements using DEA assumes that when the hotel communicates attributes of quality in advertising and manages to ask for a premium for these attributes, its advertisement will be effective. This argument was 
presented and discussed in Israeli and Uriely (2000), Israeli et al. (2001) and Israeli (2002).

The next section introduces the presentation and formulation of DEA procedures employed in the analysis. The third section presents the various ranking methods used in the study. Section four illustrates how the effectiveness of hotel advertisements can be evaluated using all the models presented in part three. Finally, the findings are presented along with conclusions and recommendations for future applications and research.

\section{Data envelopment analysis}

DEA is a procedure designed to measure the relative efficiency in cases where there are multiple inputs and multiple outputs and no obvious objective as to how to aggregate both inputs and outputs into a meaningful index of productive efficiency (Sexton et al., 1994). DEA was developed by Charnes, Cooper and Rhodes (CCR) (1978), and the method provides a mechanism for measuring the efficiency of each Decision-Making Unit (DMU). The mechanism is extensively employed in diverse industries and environments (an extensive review of DEA applications is provided by Seiford, 1996). In the service sector, applications of DEA include education (Sexton et al., 1994), recreation and health care management (Sherman, 1984) to name just a few.

The efficiency in DEA is termed Technical and Scale Efficiency (TSE), and the relative efficiency of a DMU is defined as the ratio of its total weighted output to its total weighted input. The question is how to select the weights if no unit values can be assigned to the inputs and outputs. Here lies the core of the DEA procedure. DEA permits each DMU to select any weight for each input and output, provided that it satisfies certain reasonable conditions: first that no weights can be negative, and second that the weights must be universal, meaning that the resulting ratio should not exceed 1. The BCC model, named after Banker, Charnes and Cooper (1984) allows the production function to exhibit non-constant return to scale (Banker and Chang, 1995), while the CCR model imposes the additional assumption of constant returns to scale on the production function.

The Technical and Scale Efficiency (TSE) with constant return to scale is computed according to the CCR model (Charnes, Cooper and Rhodes, 1978). Consider $n$ DMUs, when each DMU $j(j=1, \ldots, n)$ uses $m$ inputs $X_{j}=\left(X_{1 j}, X_{2 j}, \ldots, X_{m j}\right)^{T}>0$ for producing $s$ outputs $Y_{j}=\left(Y_{1 j}, Y_{2 j}, \ldots, Y_{s j}\right)^{T}>0$. The CCR model is as follows:

$$
\operatorname{Max} E_{k}=\frac{\sum_{r=1}^{s} U_{r}^{k} Y_{r k}}{\sum_{i=1}^{m} V_{i}^{k} X_{i k}}
$$

S.T

$$
\begin{aligned}
& \frac{\sum_{r=1}^{s} U_{r}^{k} Y_{r j}}{\sum_{i=1}^{m} V_{i}^{k} X_{i j}} \leq 1 \quad \quad \quad j=1,2 \ldots . n \\
& U_{r}^{k} \geq 0 \quad V_{i}^{k} \geq 0 \\
& r=1,2 \ldots . . \quad i=1,2 \ldots m
\end{aligned}
$$

The weights are all positive and the ratios are bounded by $100 \%$. Each unit $k$ is assigned the highest possible efficiency score by choosing the most optimal weights. If a unit reaches the maximum possible value of $100 \%$ it is considered efficient, otherwise it is inefficient.

The formulation of (1) can be translated into a linear program, which can be solved relatively easily, and a complete DEA solves $n$ linear programs, one for each unit.

$$
\begin{array}{ll}
\operatorname{maximize} & h_{k}=\sum_{r=1}^{S} U_{r}^{k} Y_{r k} \\
\text { subject to } & \sum_{i=1}^{m} V_{i}^{k} X_{i k}=1 \\
& \sum_{r=1}^{S} U_{r}^{k} Y_{r j}-\sum_{i=1}^{m} V_{i}^{k} X_{i j} \leq 0 \quad j=1,2, . ., n \\
& U_{r}^{k} \geq \varepsilon \quad r=1,2, . ., S \\
& V_{i}^{k} \geq \varepsilon \quad i=1,2, \ldots, m
\end{array}
$$

Where $\varepsilon$ is defined as an infinitesimal constant (a non-Archimedean quantity).

According to the model, $\mathrm{h}_{\mathrm{k}}$ denotes the TSE efficiency for $\mathrm{DMU}_{\mathrm{K}}$. If $h_{k}=1, \mathrm{DMU}_{\mathrm{K}}$ is defined as efficient, and if $h_{k}<1, \mathrm{DMU}_{\mathrm{K}}$ is not efficient.

The dual to (2) is:

$$
\text { minimize } \theta_{k}-\varepsilon\left(\sum_{r=1}^{s} S_{r k}^{+}+\sum_{i=1}^{m} S_{i k}^{-}\right)
$$

subject to

$$
\begin{gathered}
\sum_{j=1}^{n} X_{i j} \lambda_{j}+S_{i k}^{-}=\theta X_{k} \quad i=1,2, \ldots, m \\
\sum_{j=1}^{n} Y_{r j} \lambda_{j}-S_{r k}^{+}=Y_{r k} \quad r=1,2, \ldots, s \\
\lambda_{j} \geq 0 \quad j=1,2, \ldots, n \\
S_{r k}^{+}, S_{i k}^{-} \geq 0 \quad r=1,2, \ldots, s, \quad i=1,2, \ldots, m
\end{gathered}
$$


The BCC model (Banker et al., 1984) computes Technical Efficiency (TE) with increasing returns to scale. It can be defined by adding the constraint $\sum_{j=1}^{n} \lambda_{j}=1$

\section{Ranking methods}

As previously mentioned, the DEA does not rank efficient DMUs, but rather ranks the inefficient DMUs. The DEA also separates the DMUs into two different groups: efficient (with efficiency ratio of 1), and inefficient (with a ratio less than 1). Next, we present six ranking methods in the DEA context (for further information see Adler et al., 2002).

\section{Anderson and Peterson (A\&P) Method}

Anderson and Peterson, (1993) developed a new method for ranking only the efficient units because all of them received the score of 1 , while the inefficient units are ranked according the DEA scores. The method enables an efficient unit $k$ to achieve a score greater than one. The formulation is given in (4)

$$
\begin{array}{ll}
\text { maximize } & h_{k}=\sum_{r=1}^{s} U_{r}^{k} Y_{r k} \\
\text { subject to } & \sum_{i=1}^{m} V_{i}^{k} X_{i k}=1 \\
& \sum_{r=1}^{s} U_{r}^{k} Y_{r j}-\sum_{i=1}^{m} V_{i}^{k} X_{i j} \leq 0 \quad \forall j \neq k \\
U_{r}^{k} \geq \varepsilon \quad r=1,2, . ., s \\
V_{i}^{k} \geq \varepsilon \quad i=1,2, \ldots, m
\end{array}
$$

\section{The Cross Efficiency (CE) Method}

The Cross Efficiency matrix was first developed by Sexton et al. (1986). This method calculated the efficiency score of each unit $\mathrm{n}$ time using the optimal weights evaluated by each run. The results of all the DEA cross efficiency are summarized in a matrix as given in (5)

$h_{k j}=\frac{\sum_{r=1}^{s} U_{r}^{k} Y_{r j}}{\sum_{i=1}^{m} V_{i}^{k} X_{i j}} \quad j=1,2, . ., n \quad k=1,2, . ., n$

Thus $h_{k j}$ represents the score given to unit $j$ by the optimal weights of unit $k$. The elements in the diagonal $h_{k k}$ represent the standard DEA scores $h_{k}$. The Cross

Efficiency ranking method utilized the matrix $h_{k j}$ for ranking the units one scale. If we define $\bar{h}_{k}=\frac{\sum_{j=1}^{n} h_{k j}}{n}$ as the average cross efficiency score for unit $k$, all the units can be ranked on a single scale according to $\bar{h}_{k}$.

This score better represents the unit $k$ evaluation than the DEA score as it utilizes the weights of all other units, and for each unit all the inputs and outputs are evaluated with the same set of weights.

Analytic Hierarchy Process/DEA Method (AHP/DEA)

AHP/DEA uses the Analytical Hierarchical Process (AHP) proposed by Saaty (1980) and uses pairwise comparisons to rank order the DMUs. In the first step, the efficiency of each DMU is computed, as is the ratio between each pair. Then, in the second step, the correspondence between the own eigenvector and the maximum eigenvalue provides the ranking for each DMU (Sinuany-Stern et al., 2000).

\section{The Global Efficiency (GE) Method}

The Global Efficiency method finds a common weight for all the units that maximizes the sum of efficiency scores of all the units. Each efficiency score has the same structure as in the DEA, where the unit score is bound by 1 .

The formulation of GE is as follows:

$$
\begin{gathered}
\operatorname{maximize} \sum_{k=1}^{n} E_{k}^{*} \\
\text { subject to } \quad E_{k}^{*}=\frac{\sum_{r=1}^{s} U_{r} Y_{r k}}{\sum_{i=1}^{m} V_{i} X_{i k}} \leq 1 \quad k=1,2, . ., n \\
U_{r} \geq 0 \quad r=1,2, . ., s \\
V_{i} \geq 0 \quad i=1,2, \ldots, m
\end{gathered}
$$

The ranking is based on the efficiency score with the common weights $E_{k}^{*}$. For further information, see Friedman and Hadad (2002).

\section{The Discriminant Analysis of Ratio (DR) Method}

This method is based on the classification of the units into two groups: efficient and inefficient from the DEA. Then, the common weights for the composite outputs $W_{j}$ and composite inputs $Z_{j}$ are found by maximizing the ratio of the variance between the two groups and the variance within the groups. According to the ratio $T_{j}=\frac{W_{j}}{Z_{j}}$ with the common weights, all the units can be ranked on a single scale. If any weight is negative, the non-negative constraints then need to be added to the optimization problem. For further 
information see Sinuany-Stern and Friedman (1998). The Canonical Correlation Analysis (CCA) Method

The Canonical Correlation Analysis is an extension of regression analysis. It finds the optimal common weights of the multiple outputs and multiple inputs, so as to maximize the coefficient of correlation between composite inputs $Z_{j}=\sum_{i=1}^{m} V_{i} X_{i j}$ and composite outputs $W_{j}=\sum_{r=1}^{S} U_{r} Y_{r j}$. Friedman and Sinuany-Stern (1997) utilize the CCA method for ranking the units using the ratio score $T_{j}=\frac{W_{j}}{Z_{j}}$. When using the CCA method, some of the common weights may receive negative values, and thus they cannot be used here for ranking unless a constraint that $U_{r}$ and $V_{i}$ has to be positive is added.

For further information see Friedman and SinuanyStern (1997).

\section{Average Method}

Each of the six ranking methods has a different criterion for calculating the score that serves as the basis for ranking the units. The decision maker has to decide on the "best" ranking model. The probability that all the ranking methods will yield an agreement as to which alternative will be ranked first is very low. It is therefore proposed here that a method combining all the ranks of all the methods to one rank-score be used in the following manner:

$\underline{\text { Step } 1}$ - Find the rank $T_{i j}$ of each alternative $j(j=1, . ., n)$ by ranking method $i(i=1, . ., K)$.

$\underline{\text { Step } 2}$ - Calculate the average rank of each alternative $j-\bar{T}_{j}$ as follows:

$$
\bar{T}_{j}=\frac{\sum_{i=1}^{K} T_{i j}}{K} j=1,2, . ., n .
$$

Step 3 - Calculate the correlations of each of the ranking methods with the average rank score.

Step 4 - The methods that are not highly correlated significantly will be deleted by the following procedure:

Let us define the following notations -

$\rho_{0}$ - Desirable correlation coefficient.

$r_{i, a v e}$ - Correlation coefficient in sample of size $n$ between the rankings of method $i$ and the rankings by the average.

$Z_{\alpha}$ - The critical point of the standard normal distribution with significant level $\alpha$.

To test the hypothesis $\begin{aligned} & H_{0}: \rho \geq \rho_{0} \\ & H_{1}: \rho<\rho_{0}\end{aligned}$

The critical point $Z=\frac{\sqrt{n-3}}{2} \ln \left[\frac{(1+r)\left(1-\rho_{0}\right)}{(1-r)\left(1+\rho_{0}\right)}\right]$.

(For more information see Walpole and Myers, 1990).

If

$$
r_{i, a v e .}<\frac{e^{\frac{2 Z_{\alpha}}{\sqrt{n-3}}}\left(1+\rho_{0}\right)-\left(1-\rho_{0}\right)}{e^{\frac{2 Z_{\alpha}}{\sqrt{n-3}}}\left(1+\rho_{0}\right)+\left(1-\rho_{0}\right)}
$$

then we reject $H_{0}$. Namely we will delete the ranking method $\mathrm{i}$ and return to step 2 .

\section{Data}

The data set of this study included advertisements in an informative supplement of a popular national newspaper in Israel. The supplement was titled "Vacations and Hotels in Israel - December 1998, January 1999" (Rechtman, November 27, 1999). This dataset was selected because it included advertisements of hotels in a uniform format. Therefore the effectiveness of the advertisements can be computed based on the information it provides, thus creating a common basis for comparison between advertisements with no variations attributed to flashy designs, graphics, ad location and ad size. The advertisements were placed in the newspaper supplement. The top of each advertisement consisted of the hotel's name and its corporate affiliation (if any), in the middle a picture of the hotel appeared, and at the bottom was a statement giving the hotel's price per person in a double room and contact information (address, telephone). On the right-hand side of each advertisement were five small icons, which reported whether the hotel offered certain amenities or services. These included a swimming pool, activities for children, adult activities, sports facilities and handicapped accessibility (not required by law in all public buildings in Israel). If the service was offered, the icon appeared in the advertisement; otherwise it did not. The information on the hotels that elected to participate in the newspaper supplement was collected, generating a database consisting of 52 hotels.

An important issue in employing DEA is the selection of inputs and outputs. In this study, the selection was 
motivated by two factors. The first was the governing reasoning behind the use of advertisement. In advertising, a firm communicates attributes in an effort to be able to charge or justify a certain (preferably premium) price (Nagle, 1987). This analysis focuses on a supply-side perspective and posits that an advertisement will be considered effective if it supports the advertiser wish for posting a premium price. Consequently, prices are considered as outputs. The second factor that motivated the selection of inputs and outputs was the availability of information to the consumer. The inputs, or the hotel attributes, were included in the advertisement supplement that was analyzed. The outputs were the room prices as advertised in the hotel association guide. The data sources were reliable public and official publications and they were, therefore, considered suitable for the analysis.

As mentioned previously, the inputs collected from the advertisement supplement included a total of five attributes. These attributes were:

$\begin{array}{ll}X_{1} & \text { swimming pool } \\ X_{2} & \text { activities for children } \\ X_{3} & \text { adult activities } \\ X_{4} & \text { sports activities } \\ X_{5} & \text { number of rooms }\end{array}$

The outputs in the dataset included room prices for:

$\begin{array}{ll}Y_{1} & \text { high season }(H S) \\ Y_{2} & \text { regular season }(R S) \\ Y_{3} & \text { low season }(L S),\end{array}$

which were published in the Israel Hotel Guide (Israel Hotel Association, 1999).

The treatment to the binary variables $X_{1}, X_{2}, X_{3}, X_{4}$ was to assign 1 if the attribute was not offered and 2 if the attribute was available. This treatment is consistent with the procedure offered by Cooper et al. (2000, p. 167). The data on 52 hotels with 5 inputs and 3 outputs are provided in Table 1.

\section{Results}

We run the DEA procedures on the 52 hotels with 5 inputs and 3 outputs. The DEA classifies hotels into two groups, efficient and inefficient. We then rank the hotels by the six ranking methods. For each model we generate a rank between 1 and 52, where 1 denotes the highest rank. All the ranks by the six ranking methods and the DEA scores are provided in Table 2. We calculate the average of six ranks received for the six ranking methods for each hotel, and again we rank the hotels according the average rank. The ranking according the average score is also provided in Table 2.

The correlations between the pairs of each ranking method and between each method and the average method are given in Table 3. A correlation of at least 0.9 indicates a high fit among each ranking method and the average method. The critical value of the sample coefficient of correlation to delete a method that is not significantly correlated with the average ranking method is less than a critical $r$. For example if $\alpha=0.05$ and $\rho_{0}=0.9$, and sample size $n=52$, the critical $r$ is 0.845 . Based on the critical value we deleted the GE from further consideration, and the average ranking method averaged only five ranking methods. These two average models are also included in Table 2.

The average ranking of six models and the new average ranking with five models were highly correlated (0.99). The information in Table 2 illustrates the difference between the rankings of each hotel. Even if these differences are not significant, the alternatives (hotels) ranked in the first places were not identical. Consequently, the decision maker cannot decide on the best alternative. For example, using the first average method, the Dan Pearl Hotel was ranked first and the King David Hotel ranked second. When using the new average method, the rankings were switched. Furthermore, the correlation between the new average ranking method and the other five ranking methods was improved after deleting the GE method. All the coefficients of the correlation were above 0.9 and are provided in Table 3 .

\section{Conclusions and future research}

From a technical perspective, this case study demonstrated that the DEA techniques can be used to evaluate the effectiveness of hotel advertisements. This can be applied in the future to improve the effectiveness of marketing efforts. Another issue regards the inclusion of binary variables in the DEA following the principles offered by Cooper et al. (2000). In the case study presented here, part of the information was presented in a binary format to denote input that may or may not exist, for example, the variable for activities for children exists only at some hotels. The King David Hotel has low inputs (most of the binary variables receive the low score of 1 ), while the outputs were very high, making this hotel efficient. At the Mercure Hotel all its binary variable are high (score of 2), but the outputs are very low relatively, 
Table 1. Inputs, outputs and star rating of 52 hotels in Israel

\begin{tabular}{|c|c|c|c|c|c|c|c|c|c|c|}
\hline & \multirow[t]{2}{*}{ DMU } & \multirow{2}{*}{\begin{tabular}{|c|} 
Pool \\
$X_{1}$ \\
\end{tabular}} & \multirow{2}{*}{\begin{tabular}{|c|} 
Kids \\
$\mathrm{X}_{2}$ \\
\end{tabular}} & \multicolumn{2}{|c|}{ Adult Sport } & \multirow{2}{*}{$\begin{array}{c}\text { Rooms } \\
\mathrm{X}_{\mathbf{5}}\end{array}$} & \multirow{2}{*}{$\begin{array}{c}\text { HS } \\
Y_{1} \\
\end{array}$} & \multirow{2}{*}{$\begin{array}{l}\mathbf{R S} \\
\mathbf{Y}_{2} \\
\end{array}$} & \multirow{2}{*}{$\begin{array}{l}\mathrm{LS} \\
\mathrm{Y}_{3} \\
\end{array}$} & \multirow{2}{*}{$\begin{array}{c}\text { Star } \\
\text { Rating }\end{array}$} \\
\hline & & & & $\mathbf{X}_{3}$ & $\mathbf{X}_{4}$ & & & & & \\
\hline 1 & Ambassador & 2 & 2 & 2 & 2 & 216 & 242 & 196 & 178 & 4 \\
\hline 2 & Americana & 2 & 2 & 2 & 2 & 130 & 120 & 99 & 88 & 2 \\
\hline 3 & Ariel & 1 & 1 & 1 & 1 & 128 & 135 & 115 & 115 & 4 \\
\hline 4 & Astoria & 2 & 1 & 1 & 1 & 65 & 106 & 87 & 82 & 2 \\
\hline 5 & Caesar Eilat & 2 & 2 & 2 & 2 & 241 & 182 & 167 & 133 & 4 \\
\hline 6 & Carlton Dead Sea & 2 & 2 & 2 & 2 & 244 & 175 & 136 & 136 & 4 \\
\hline 7 & Carlton Tel Aviv & 2 & 1 & 1 & 2 & 281 & 242 & 217 & 177 & 5 \\
\hline 8 & Carmel Beach & 2 & 2 & 2 & 2 & 90 & 305 & 280 & 260 & 4 \\
\hline 9 & Carmel Mountain & 1 & 2 & 2 & 1 & 99 & 70 & 70 & 70 & 3 \\
\hline 10 & Crown Plaza Dead Sea & 2 & 2 & 2 & 2 & 302 & 250 & 240 & 218 & 5 \\
\hline 11 & Crown Plaza Eilat & 2 & 2 & 2 & 2 & 266 & 328 & 218 & 218 & 5 \\
\hline 12 & Crown Plaza Tel Aviv & 2 & 2 & 2 & 2 & 246 & 378 & 318 & 318 & 5 \\
\hline 13 & Dan Carmel & 2 & 2 & 2 & 2 & 219 & 306 & 266 & 252 & 5 \\
\hline 14 & Dan Eilat & 2 & 2 & 2 & 2 & 378 & 535 & 345 & 270 & 5 \\
\hline 15 & Dan Panorama & 2 & 2 & 2 & 2 & 266 & 242 & 232 & 207 & 5 \\
\hline 16 & Dan Panorama Tel Aviv & 2 & 2 & 2 & 2 & 500 & 261 & 222 & 222 & 5 \\
\hline 17 & Dan Pearl & 2 & 2 & 2 & 2 & 104 & 423 & 311 & 311 & 5 \\
\hline 18 & Dvir & 2 & 2 & 1 & 1 & 30 & 69 & 69 & 69 & 3 \\
\hline 19 & Edom Mountain & 2 & 2 & 2 & 2 & 110 & 118 & 100 & 88 & 3 \\
\hline 20 & Edomit & 2 & 1 & 2 & 1 & 85 & 120 & 96 & 93 & 3 \\
\hline 21 & Holiday Inn Patio & 2 & 2 & 2 & 2 & 115 & 145 & 115 & 115 & 4 \\
\hline 22 & Holiday Inn Tiberias & 2 & 2 & 2 & 2 & 246 & 238 & 180 & 173 & 4 \\
\hline 23 & King David & 1 & 1 & 1 & 2 & 237 & 472 & 394 & 394 & 5 \\
\hline 24 & King Solomon & 2 & 2 & 2 & 2 & 419 & 346 & 240 & 176 & 5 \\
\hline 25 & Laguna & 2 & 2 & 2 & 1 & 256 & 234 & 213 & 175 & 4 \\
\hline 26 & Melody & 1 & 1 & 1 & 1 & 34 & 125 & 117 & 113 & 4 \\
\hline 27 & Mercure Jerusalem & 1 & 1 & 1 & 1 & 298 & 140 & 115 & 95 & 4 \\
\hline 28 & Mercure & 2 & 2 & 2 & 2 & 159 & 130 & 110 & 100 & 4 \\
\hline 29 & Moon Valley & 2 & 2 & 2 & 1 & 182 & 130 & 100 & 90 & 2 \\
\hline 30 & Nova & 2 & 2 & 2 & 2 & 193 & 157 & 134 & 123 & 4 \\
\hline 31 & Palmira & 2 & 2 & 2 & 2 & 195 & 235 & 196 & 167 & 4 \\
\hline 32 & Princess & 2 & 2 & 2 & 2 & 420 & 588 & 307 & 281 & 5 \\
\hline 33 & Quiet Beach Tiberias & 1 & 1 & 1 & 2 & 198 & 140 & 109 & 95 & 3 \\
\hline 34 & Raddisson Moria Dead Sea & 2 & 2 & 2 & 2 & 196 & 230 & 200 & 200 & 5 \\
\hline 35 & Raddisson Moria Plaza & 2 & 2 & 2 & 2 & 306 & 280 & 250 & 250 & 5 \\
\hline 36 & Raddisson Moria Plaza Dead Sea & 2 & 2 & 2 & 2 & 220 & 290 & 250 & 250 & 5 \\
\hline 37 & Raddisson Moria Plaza Jerusalem & 2 & 2 & 2 & 2 & 292 & 235 & 215 & 185 & 5 \\
\hline 38 & Raddisson Moria Plaza Tel Aviv & 2 & 2 & 2 & 2 & 355 & 245 & 225 & 195 & 5 \\
\hline 39 & Raddisson Moria Plaza Tiberias & 2 & 2 & 2 & 2 & 272 & 275 & 255 & 210 & 5 \\
\hline 40 & Ramada Continental & 2 & 2 & 2 & 2 & 340 & 213 & 183 & 183 & 5 \\
\hline 41 & Reef & 2 & 1 & 2 & 1 & 79 & 155 & 132 & 127 & 3 \\
\hline 42 & Royal Beach & 2 & 2 & 2 & 2 & 363 & 666 & 457 & 309 & 5 \\
\hline 43 & Royal Plaza Jerusalem & 1 & 1 & 1 & 2 & 300 & 200 & 144 & 144 & 4 \\
\hline 44 & Royal Plaza Tiberias & 1 & 2 & 2 & 2 & 160 & 194 & 162 & 162 & 4 \\
\hline 45 & Sheraton Eilat & 2 & 2 & 2 & 2 & 247 & 207 & 155 & 137 & 5 \\
\hline 46 & Sheraton Four Point & 2 & 2 & 2 & 2 & 282 & 217 & 185 & 165 & 4 \\
\hline 47 & Sheraton Jerusalem & 2 & 2 & 2 & 2 & 296 & 317 & 277 & 191 & 5 \\
\hline 48 & Sheraton Plaza Jerusalem & 2 & 2 & 2 & 2. & 296 & 317 & 277 & 191 & 5 \\
\hline 49 & Sport & 2 & 2 & 2 & 2 & 327 & 229 & 188 & 143 & 4 \\
\hline 50 & Tiberias Hotel & 2 & 1 & 1 & 2 & 70 & 130 & 96 & 96 & 3 \\
\hline 51 & Topaz & 2 & 2 & 2 & 1 & 81 & 120 & 110 & 97 & 3 \\
\hline 52 & Vista & 2 & 2 & 2 & 1 & 84 & 144 & 115 & 104 & 3 \\
\hline
\end{tabular}


Table 2. DEA efficiency score and the ranking of the hotels

\begin{tabular}{|c|c|c|c|c|c|c|c|c|c|}
\hline & & & & & ng Me & & & & \\
\hline Unit & DEA & A\&P & CE & AHP & GE & DR & $\mathrm{CCA}$ & Average * & Average ** \\
\hline 1 & 0.5153 & 33 & 21 & 21 & 23 & 21 & 26 & 23 & 25 \\
\hline 2 & 0.3025 & 52 & 49 & 46 & 35 & 44 & 52 & 48.5 & 51 \\
\hline 3 & 0.5838 & 22 & 37 & 28 & 27 & 20 & 18 & 28 & 26 \\
\hline 4 & 0.5317 & 32 & 42 & 29 & 11 & 29 & 27 & 30 & 32 \\
\hline 5 & 0.4217 & 42 & 33 & 49 & 39 & 39 & 37 & 39 & 42 \\
\hline 6 & 0.357 & 48 & 43 & 51 & 46 & 49 & 47 & 52 & 49 \\
\hline 7 & 0.5508 & 25 & 19 & 20 & 32 & 28 & 25 & 25.5 & 23 \\
\hline 8 & 1 & 5 & 4 & 3 & 3 & 2 & 4 & 3 & 3 \\
\hline 9 & 0.3787 & 45 & 52 & 48 & 42 & 45 & 49 & 50 & 50 \\
\hline 10 & 0.5854 & 21 & 17 & 26 & 33 & 27 & 24 & 24 & 21 \\
\hline 11 & 0.614 & 20 & 15 & 11 & 26 & 19 & 17 & 15 & 15 \\
\hline 12 & 0.8071 & 9 & 5 & 4 & 10 & 6 & 5 & 6 & 5 \\
\hline 13 & 0.6949 & 10 & 8 & 6 & 13 & 7 & 9 & 7.5 & 8 \\
\hline 14 & 0.8396 & 8 & 6 & 8 & 16 & 8 & 7 & 7.5 & 6.5 \\
\hline 15 & 0.5679 & 23 & 16 & 22 & 29 & 23 & 20 & 20.5 & 19 \\
\hline 16 & 0.5635 & 24 & 29 & 37 & 51 & 51 & 40 & 38 & 36 \\
\hline 17 & 1 & 2 & 2 & 2 & 1.5 & 1 & 2 & 1 & 2 \\
\hline 18 & 0.692 & 11 & 45 & 25 & 4 & 31 & 34 & 27 & 29 \\
\hline 19 & 0.3177 & 51 & 48 & 41 & 28 & 36 & 50 & 44 & 47 \\
\hline 20 & 0.5452 & 28 & 44 & 30 & 15 & 33 & 31 & 31 & 35 \\
\hline 21 & 0.3618 & 47 & 40 & 35 & 20 & 30 & 44 & 36 & 40 \\
\hline 22 & 0.4715 & 37 & 28 & 34 & 34 & 32 & 32 & 34 & 33 \\
\hline 23 & 1 & 1 & 1 & 1 & 5 & 4 & 1 & 2 & 1 \\
\hline 24 & 0.5453 & 27 & 23 & 32 & 43 & 35 & 28 & 32 & 28 \\
\hline 25 & 0.9991 & 6 & 22 & 31 & 30 & 26 & 10 & 19 & 17 \\
\hline 26 & 1 & 4 & 14 & 10 & 1.5 & 3 & 6 & 5 & 6.5 \\
\hline 27 & 0.5405 & 30 & 50 & 40 & 52 & 52 & 45 & 46 & 44 \\
\hline 28 & 0.3185 & 50 & 47 & 50 & 38 & 47 & 51 & 51 & 52 \\
\hline 29 & \begin{tabular}{|l|l|}
0.4892 \\
\end{tabular} & 36 & 51 & 52 & 48 & 50 & 41 & 48.5 & 48 \\
\hline 30 & 0.3656 & 46 & 41 & 47 & 37 & 41 & 46 & 45 & 45 \\
\hline 31 & 0.3951 & 43 & 20 & 17 & 19 & 16 & 22 & 22 & 24 \\
\hline 32 & 0.8965 & 7 & 7 & 9 & 25 & 12 & 8 & 10 & 9 \\
\hline 33 & 0.3357 & 49 & 46 & 39 & 47 & 42 & 48 & 47 & 46 \\
\hline 34 & 0.5429 & 29 & 18 & 16 & 18 & 15 & 21 & 16.5 & 18 \\
\hline 35 & 0.6345 & 17 & 13 & 15 & 31 & 25 & 19 & 18 & 16 \\
\hline 36 & 0.6521 & 15 & 9 & 7 & 14 & 9 & 12 & 9 & 10 \\
\hline 37 & 0.5133 & 34 & 24 & 36 & 36 & 34 & 29 & 33 & 31 \\
\hline 38 & 0.5387 & 31 & 25 & 38 & 44 & 38 & 33 & 35 & 34 \\
\hline 39 & 0.6197 & 19 & 12 & 13 & 24 & 17 & 15 & 14 & 13 \\
\hline 40 & 0.4645 & 38 & 31 & 43 & 49 & 48 & 39 & 43 & 41 \\
\hline 41 & 0.6521 & 16 & 26 & 12 & 6 & 11 & 11 & 11 & 14 \\
\hline 42 & 1 & 3 & 3 & 5 & 7 & 5 & 3 & 4 & 4 \\
\hline 43 & 0.4237 & 41 & 38 & 24 & 50 & 46 & 43 & 41.5 & 38 \\
\hline 44 & 0.5045 & 35 & 27 & 14 & 17 & 10 & 30 & 20.5 & 22 \\
\hline 45 & 0.3951 & 44 & 34 & 45 & 41 & 40 & 38 & 41.5 & 43 \\
\hline 46 & 0.4479 & 39 & 30 & 42 & 40 & 37 & 35 & 37 & 37 \\
\hline 47 & 0.6541 & 13 & 10 & 18 & 21 & 13 & 13 & 12 & 11 \\
\hline 48 & 0.6541 & 14 & 11 & 19 & 22 & 14 & 14 & 13 & 12 \\
\hline 49 & 0.4285 & 40 & 32 & 44 & 45 & 43 & 36 & 40 & 39 \\
\hline 50 & \begin{tabular}{|l|}
0.5489 \\
\end{tabular} & 26 & 36 & 23 & 8 & 22 & 42 & 29 & 30 \\
\hline 51 & 0.6336 & 18 & 39 & 33 & 12 & 24 & 23 & 25.5 & 27 \\
\hline 52 & 0.6554 & 12 & 35 & 27 & 9 & 18 & 16 & 16.5 & 20 \\
\hline
\end{tabular}

*- Average over six ranking methods.

**- Average over five ranking methods (deleting GE). 
Table 3. Spearman correlation between ranking methods and hotel star rating

\begin{tabular}{|c|c|c|c|c|c|c|c|c|}
\hline & CE & AHP & GE & DR & CCA & Average * & Average ** & $\begin{array}{c}\text { Star } \\
\text { Rating }\end{array}$ \\
\hline A\&P & 0.751 & 0.806 & 0.670 & 0.777 & 0.903 & 0.891 & 0.906 & -0.387 \\
\hline CE & & 0.841 & 0.491 & 0.807 & 0.880 & 0.883 & 0.914 & -0.747 \\
\hline AHP & & & 0.758 & 0.922 & 0.873 & 0.9481 & 0.947 & -0.439 \\
\hline GE & & & & 0.865 & 0.697 & 0.798 & $/$ & 0.029 \\
\hline DR & & & & & 0.899 & 0.959 & 0.933 & -0.341 \\
\hline CCA & & & & & & 0.963 & 0.970 & -0.472 \\
\hline Average * & & & & & & & 0.990 & -0.451 \\
\hline Average ** & & & & & & & & -0.516 \\
\hline
\end{tabular}

*- Average over six ranking methods.

**- Average over five ranking methods (deleting GE).

meaning that this hotel's advertisements are ineffective and it ranked in last place. Another purpose of the case study was to examine the correlation between the rankings of the star ratings for each hotel (from 2-5) (Table 1). The GE has the least coefficient of correlation with the star rating (0.03), while the highest was the CE (0.74). All the others spanned between $0.35-0.47$.

Another aspect that was investigated in Table 3 was the correlation between the effectiveness of hotel advertising and their quality rating or star rating. Under the star rating system, hotels can be awarded up to 5 stars based on the level of service offered. This was monitored by a special code published by the Israeli Ministry of Tourism. Despite the popularity of the star rating system in Israel and around the world, and despite the reliance of hotels on this system as a justification for pricing (Israeli, 2002, Israeli et al., 2001), pressures were mounting on the system by investors to "bend the rules" and assign high star ratings to hotels that did not meet the standards. Additionally, short-term manipulations of the hotel facilities, carried out only when the star-rating reviewers inspected the hotel, became popular among many businesses. Given that the aforementioned activities effectively decreased the validity and reliability of the star rating system and as inspection and enforcement of the code became too expensive, the Ministry of Tourism decided not to use the system in Israel. Regardless of the decision of the Ministry not to enforce the star rating system, hotels continue to advertise and communicate the star rating that they had before the ranking system was terminated. Moreover, Israeli and Uriely (2000) and Israeli (2002) clearly demonstrate that hotels use their star rating as a signal of quality, to justify a request for a premium price.

One surprising finding was that the correlation between the star rating and each of the ranking methods was very low (see Table 3 ). Moreover, this finding may be rooted in the context that was examined. The need to engage in advertising was triggered by a certain problem in performance in the overall context of a growing crisis in the industry. In other words, if hotels did not face problems with demand they would probably not turn to advertising. When a problem arises, and advertising is used, it may signal that the advertiser is facing a problem. From this weak position, the hotel may offer its infrastructure at a lower price to increase consumption. This fact may lead to a low correspondence between the effectiveness of the advertisement and the overall quality rating of the hotel (as signaled by the star rating).

Another aspect examined was the correlation between the ranking of the hotel advertisement using the different DEA methods and star rating of these hotels (provided in Table 1). The high correlations between the different ranking methods indicate that even when each ranking method has a different objective function, all of them are highly correlated. Nevertheless, even when the different methods are correlated, the ranking of hotels, particularly in the first few places are different. To help the decision maker decide exactly what the best alternative is, it is suggested that the decision maker choose one ranking method based on the average ranking methods that are significantly correlated.

Pricing strategic assets is a problematic issue that has been addressed in past research (Israeli, 2002, Israeli et al., 2001, Israeli and Uriely, 2000, and Lewis and Chambers, 1989). This paper demonstrates how hotels can craft an effective advertisement if they know how to assign the right price to the attributes (or assets) they own and communicate effectively in the advertisement. This paper does not examine the effectiveness of an advertisement as a function of the demand it generates. Given that this is an important output of advertisement, it is suggested that future 
research address the marginal change in demand in the calculation of advertisement effectiveness.

\section{Acknowledgement}

This paper was partially supported by the Paul Ivanier Center for Robotics and Production Management, Ben-Gurion University of the Negev.

\section{References}

Adler, N., Friedman, L. and Sinuany-Stern, Z. (2002) Review of Ranking Methods in the DEA Context. European Journal of Operational Research, 140, p. 249-265.

Andersen, P. and Petersen, N. C. (1993) A Procedure for Ranking Efficient Units in Data Envelopment Analysis. Management Science, Vol. 39, No. 10, p. 1261-1264.

Batra, R. J., Myers, G. and Aaker, D. A. (1996) Advertising Management, Prentice Hall, Inc., Upper Saddle River, NJ.

Banker, R. D., Charnes A. and Cooper, W. W. (1984) Some Models for Estimating Technical and Scale Inefficiencies in Data Envelopment Analysis. Management Science, 30, p. 1078-1092.

Banker, R. D. and Chang, H. (1995) A Simulation Study of Hypothesis Tests for Differences in Efficiencies. International Journal Production Economist, 39, p. 3754.

Charnes, A., Cooper, W.W. and Rhodes, E. (1978) Measuring the Efficiency of Decision Making Units, European Journal of Operational Research, Vol. 2, p. 429-444.

Cooper, W. W., Seiford, M. L. and Kaoru, T. (2000) Data Envelopment Analysis, Kluwer Academic Publishers, Second printing.

Friedman, L. and Hadad Yossi. (2002) Common Weights for Ranking in the DEA Context. Communication in Dependability and Quality Management, Vol. 5(1), p. 43-55.

Friedman, L. and Sinuany-Stern, Z. (1998) Combining Ranking Scales and Selecting Variables in the DEA Context: The Case of Industrial Branches, Computers \& Operations Research, Vol. 25, No. 9, p. 781-791.

Friedman, L. and Sinuany-Stern, Z. (1997) Scaling Units via the Canonical Correlation Analysis in the DEA Context, European Journal of Operational Research, Vol. 100, No. 3, p. 629-637.

Israeli Hotel Association. The Israeli Hospitality Industry - National Conference. Tel Aviv (in Hebrew) (1999).

Israeli, A. (2002) Star Rating and Corporate Affiliation: Their Influence on Pricing Hotel Rooms in Israel. International Journal of Hospitality Management, 21 (4), p. 405-424.
Israeli, A., Adler, N., Mehrez, A. and Sundali, J. (2001) Investigating the Use of Advertising for Communicating Hotels' Strategic Assets. Journal of Hospitality and Leisure Marketing, Vol. 7, No. 3, p. 22-38.

Israeli, A. and Reichel, A. Hospitality Crisis Management Practices: The Israeli Case, International Journal of Hospitality Management, Forthcoming, 2004.

Israeli, A. and Uriely, N. (2000) The Impact of Star Ratings and Corporate Affiliation on Hotel Room Prices, International Journal of Hospitality and Tourism Research, Vol. 2, No. 1, p. 27-36.

Lewis, R. C. and Chambers, R. E. (1989) Marketing Leadership in Hospitality - Foundations and Practices, Van Nostrand Reinhold, New York, NY.

Mehrez, A. and Israeli, A. (2001) Factors of Satisfaction among Guest in Israeli Hotels. Central Bureau of Statistics Quarterly, Issue number, 122.

Nagle, T. T. (1987) The Strategy and Tactics of Pricing, Prentice Hall, Englewood Cliffs, NJ.

Rechtman, N. (1999) (editor) 27.11.99. Vacations and Hotels in Israel - December 1998, Ma'ariv, Israel (in Hebrew).

Saaty, T. L. (1980) The Analytic Hierarchy Process, Planning Priority Setting Resource Allocation, McGraw-Hill Book Company, New York.

Seiford, L. M. (1996) The Evolution of the State-of-art (1978-1995), Journal of Productivity Analysis, Vol. 7, p. 99-137.

Sexton, T. R., Silkman, R. H. and Hogan, A. (1986) DEA: Critique and Extensions. In R.H. Silkman (ed.), Measuring Efficiency: An Assessment of DEA. San Francisco: American Evaluation Association, Jossey Bass, Inc. p. 73-105.

Sexton, T. R., Sleeper, S. and Taggart, R. E. (1994) Jr. Improving Pupil Transportation in North Carolina, Interfaces, Jan/Feb, Vol. 24, No. 1, p. 87-104.

Sherman, H. D. (1984) Improving the Productivity of Service Businesses. Sloan Management Review, Vol. 23, No. 3, p. 11-23.

Sinuany-Stern, Z., Mehrez, A. and Hadad, Y. (2000) An AHP/DEA Methodology for Ranking Decision Making Units, International Transactions In operational Research, Vol. 7, p. 109-124.

Sinuany-Stern, Z. and Friedman, L. (1998) DEA and the Discriminant Analysis of Ratios for Ranking Units, European Journal of Operational Research, Vol. 111, p. 470-478. 